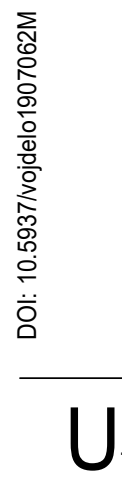

\title{
INTERNET KAO SREDSTVO ZA POLITIČKE KOMUNIKACIJE
}

\author{
Jovan Č. Mitrović \\ Ekonomski fakultet u Kosovskoj Mitrovici \\ Vladimir J. Mitrović \\ Univerzitet u Beogradu, Fakultet organizacionih nauka
} radu se analizira koliko i kako se u izbornim kampanjama koristi internet u svetu i kod nas, odnosno u kojoj meri internet utiče na informisanje birača i kako bi ga efikasno trebalo koristiti. $U$ tom smislu, sprovedeno je istraživanje kojim je ispitana važnost interneta kao sredstva informisanja birača u gradu Nišu. Rezultati istraživanja potvrdili su da internet za birače grada Niša nije toliko relevantno sredstvo informisanja o političkim strankama i kandidatima. Takođe, rezultati istraživanja potvrdili su da kandidati za gradonačelnika grada Niša do sada nisu koristili internet platformu za komunikaciju sa članovima svojih stranaka, simpatizerima i širim krugom građana.

Ključne reči: informatičko društvo, internet, političke stranke, birači, dijalog, odlučivanje

Uvod

Jpotreba interneta sve je raširenija u svetu. Zbog toga što internet karakteriše mogućnost dvosmerne komunikacije, to ako ga stranke koriste za dijalog sa svojim članovima i simpatizerima, onda će ostvari bolju stranačku mobilizaciju, a time i moguć bolji rezultat. Uz to, ako kandidati taj dijalog prošire na širi krug građana, to može doprineti i većoj izbornoj participaciji, a time i koristi društvu u celini.

$U$ tom smislu, ovaj rad ima za cilj da istraži koliko se i kako internet koristi u političkoj komunikaciji od strane stranaka, kandidata i birača i kako bi ga trebalo efikasno koristiti.

Polazi se od hipoteze da internet može doprineti boljem rezultatu na izborima samo ako stranke i kandidati iskoriste njegov potencijal za dvosmernu komunikaciju.

Da bi se dokazalo tvrđenje, sprovedeno je istraživanje kojim je ispitana važnost interneta kao sredstva informisanja birača u gradu Nišu.

\section{Informatička revolucija i nastanak informatičkog društva}

Istorijski gledano nikada jedna tehnologija nije toliko preobrazila društvene odnose i pospešila komunikaciju, među ljudima koliko je to razvoj informaciono-komunikacione tehnologije (u daljem tekstu IKT). Razvoj i upotreba IKT i njihova važnost sa aspekata društvenih odnosa koji nastaju njihovom upotrebom doveli su do stvaranja naziva "informatičko dru-

*jovan.mitrovic@pr.ac.rs 
štvo" (information society), sa novim sistemom vrednosti, običaja i navika. Ovaj naziv je po svojoj prirodi sličan nazivima građansko društvo, demokratsko društvo ili industrijsko društvo i njime se naglašava uloga informacija u današnjem društvu, kao što se ovim drugim naglašava uloga građanina, volje naroda, odnosno industrijske proizvodnje. Nastankom informatičkog društva, čovekov život, ostvarivanje ljudskih prava i celo društvo značajno su unapređeni. U "deklaraciji o principima izgradnje informatičkog društva",[1] komunikacija se opisuje kao fundamentalni socijalni proces i osnovna ljudska potreba, kao i osnova celokupne socijalne organizacije. Informatčko društvo pružilo je nove mogućnosti u smislu učešća građana tako da im se olakšava izražavanje mišljenja i stavova. Ovo je potrebno naglasiti, jer su u opštoj buci koja prati razvoj tehnologija često najglasniji povici na nove tehnologije kao na nekakvo sredstvo porobljavanja čoveka. Međutim, ako se uporede današnje mogućnosti pojedinca sa onima od pre nekoliko decenija, videće se da je današnji čovek slobodniji, informisaniji, obrazovaniji, bogatiji i zdraviji. Uz to, slobodno kretanje ljudi i kapitala uz napredak IKT doprineli su i brisanju granica koje su nametale države i sistemi.

Upravo zbog tih svojstava informatičko društvo kao postindustrijski privredni i društveni oblik, postaje relevantno pitanje sa listom ciljeva koji su od globalnog značaja. U tom smislu, do sada su održana dva svetska samita o informatičkom društvu (World Summit on the Information Society) i to 2003. godine u Ženevi i 2005, godine u Tunisu. U "Deklaraciji o principima izgradnje informatičkog društva" usvojenoj u Ženevi 2003. godine navode se zajednička vizija, ključni principi i obavezivanje na posvećenost izgradnji informatičkog društva za sve koje bi bilo bazirano na deljenju znanja. U tekstu je iskazana želja i posvećenost izgradnji društva u kome će svako moći da kreira, pristupa, koristi i deli informacije i znanja i prepoznat je potencijal IKT u promovisanju i ostvarivanju najvažnijih ciljeva usvojenih u Ujedinjenim nacijama, na primer, one koje mogu omogućiti dostupnost edukacije, znanja, informacija i komunikacije u svakom delu sveta. Kao jedan od ciljeva u deklaraciji navodi se i da postojeći digitalni jaz bude iskorenjen i da digitalne mogućnosti budu jednake za sve, nezavisno od razvijenosti zemlje ili u okviru pojedinih zemalja. I Evropska Unija stavila je informatičko društvo u centar svoje strategije za 21 vek. Između ostalog, ona je pokrenula niz akcija podrške i promociji (eEurope 2010) i usvojila je mere kojima je cilj kontrole i ograničavanje rizika povezanih s razvojem informatičkog društva poput plana delovanja za promociju sigurne upotrebe Interneta i suzbijanja nezakonitih i štetnih poruka.

Od sredine devedesetih godina mnoge države donele su posebne programe u cilju informatizacije društva. Tako su SAD donele program razvoja Nacionalne informacione infrastrukture u kome su tri povezana cilja u razvoju interneta bila dostizanje univerzalnog pristupa informacijama i komunikacionim sredstvima, proširenje obuke nastavnika i osiguranje da će relevantni sadržaji biti proizvedeni kako bi se mreža optimalno koristila. U Septembru 1999. godine Nemačka je usvojila strategiju razvoja informacionog društva koja je, između ostalog, predviđala povećanje broja korisnika interneta, opremanje škola multimedijalnim personalnim računarima, dostizanje liderske pozicije u razvoju obrazovanog softvera, integrisanje novih medija u novi pristup doživotnom obrazovanju, a kompanije čiji je prioritet bio instaliranje hardvera pod nazivom "internet za sve". [1]

I kod nas je krajem 2006. godine usvojena "Strategija razvoja informacionog društva u Republici Srbiji", a u maju 2007. godine formirano je i Ministarstvo za telekomunikacije i informatičko društvo.[2] Tri godine kasnije doneta je "Strategija razvoja informacionog društva do 2020. godine.[3] kojom su na celovit način definisani osnovni ciljevi, načela 
prioriteti razvoja informacionog društva i utvrđene aktivnosti koje treba preduzeti u periodu koji obuhvata ova strategija, kako bi Republika Srbija po pokazateljima razvijenosti informacionog društva dostigla prosek Evropske Unije.

Masovna primena IKT dovodi do velikih promena u svim oblastima poslovanja. Razvijene industrijske zemlje poprimaju sve više obeležja informacionog društva, pri čemu proizvodnja materijalnih dobara sve se više povlači pred proizvodnjom informacija, dok uticaj IKT na privredu i ostale sektore kontinuirano raste. Danas informaciona privreda čini zasebnu privrednu granu, koja već nadmašuje klasične industrijske grane po obrtu i rastu. IKT su povećale i kompetitivno okruženje i kreirale zaista istinsko globalno tržište, i mi smo sada svedoci promene u trgovini od "trgovinskih artikala" ka servisima. Danas više od 40 odsto onlajn (on-line) trgovine u SAD ide preko "Amazona" sa više od dve milijarde korisnika mesečno. Fejsbuk (Facebook) ima ključni uticaj na medijsku industriju. Firme ne mogu da posluju bez Gugla (Google) preko kojeg u pojedinim zemljama ide više od 90 odsto pretraživanja na internetu. Fejzbuk i Gugl kontrolišu dve trećine prihoda u SAD od onlajn reklamiranja.[4] Primer Finske ukazuje šta sve može biti ostvareno ne samo u domenu privrednog rasta, već i ostalim važnim aspektima funkcionisanja društva. Finska je uspela da se za relativno kratko vreme, od zemlje koja nije bila preterano razvijena, uvrsti među lidere u razvoju i primeni visokih tehnologija u čijoj strukturi IKT imaju posebno mesto i ostvari visok ekonomski rast uz socijalna davanja koja znatno nadmašuju druge razvijene zemlje.

Osim privrednog, gotovo svi ostali aspekti društvenih odnosa trpe promene uslovljene informacionim društvom. Kao i svaka nova tehnologija i IKT ima uticaja na sferu politike. Osnovni model organizacije umesto hijerarhijskog postaje mrežni. Novi mediji, u prvom redu internet sa svojim alatima i platformama, i društvenim mrežama (Facebook, Twiter, MySpace, You Tube...), omogućili su stvaranje globalnog komunikacionog sistema koji funkcioniše na principu ravnopravnog učešća i univerzalne primene svih prethodnih tradicionalnih medijskih oblika. Nastaje pojam virtuelne realnosti (ali i realne virtualnosti) ili "globalne internet kulture"[5], koja se svakim danom sve više prenosi i na politički život. Uz to, prostorna i vremenska distanca izgubile su svoju kvantitativnu vrednost, što je pružilo mogućnost za brzu i jeftinu masovnu komunikaciju. Dakle, sve ono što koristi političarima i građanima da mogu lakše da donose odluke, odnosno da učestvuju u političkim akcijama.

Za kraj, na osnovu objašnjenja o konceptu informacionog društva, možemo da identifikujemo različite neosporive osobine i zaključke koje karakterišu informatičko društvo, a to su: značenje informacija; upotreba informacionih mreža za distribuiranje informacija; radikalne promene u životima običnih ljudi kao rezultat uvećanja integracije IKT u sve sfere javnih i privatnih života; neophodnost da građani dobiju potrebno iskustvo i veštine, i da sa svojim beneficijama koje im se nude imaju pristup masovnim proširenim riznicama informacija.[6]

\section{Suština interneta i njegovih prednosti}

Internet je skup međusobno povezanih mreža provajdera (internet posrednika) i njegovih korisnika. Internet je globalna računarska mreža sastavljena iz velikog broja međusobno povezanih mreža koje koriste internet protokol (Internet protocol) za međusobnu komunikaciju. Preciznije, koristi se protokol koji se zove TCP/IP (Transmission Control Protocol Internet Protocol). Individualne računarske mreže, koje lokalno mogu da koriste različite 
protokole i standarde za razmenu podataka, uključuju se u internet preko posebnog računara označenog kao gateway koji obezbeđuje TCP/IP. Internet je neka vrsta packetswitching mreže. Računar koji šalje podatke to radi koristeći definisani protokol, a podaci se prenose kao celine u paketima. Kada se šalje veća količina podataka, podaci mogu biti poslati u više paketa, koji se istim, a često i različitim putevima prenose kroz računarsku mrežu do računara koji ih prihvata. Na mestu prijema se rekonstruišu podaci iz svih primljenih paketa. Spojena mreža računara čini internetsku mrežnu zajednicu sa nepreglednim slobodama (ne i neograničenim). Autor Babić ističe da u trijadi uređenog medijskog prostora (regulacija, koregulacija i samoregulacija), samoregulacija najbolje odražava suštinu interneta, mogućnostima u domenu komunikacije, prikupljanja informacija, multimedije...[7]

Peter Dahlgren [8] sagledava tehnološka i organizaciona svojstva interneta koja po njegovom shvatanju, daju suštinska objašnjenja neophodna za razumevanje pojma i načina delovanja interneta kao medija, a to su:

- Multimedijalnost - radi se o konvergenciji različitih oblika medija (slika, tekst, fotografije, grafike, video i audio zapisi) koji imaju zajednički digitalni oblik pomoću kojih se na internetu posreduju sadržaji koji se udružuju u multimedijalni tekst,

- Hipertekstualnost - označava veze (hiperlinkove) na druge sadržaje, koji takođe mogu sadržavati veze koje vode negde drugo. Korisnik dolazi do drugih sadržaja obično klikom na poveznice.[9]

- Interaktivnost - svaki računar povezan u mrežu može biti potencijalni provajder sadržaja, a ne samo sredstvo za razgledanje web-sajta i preuzimanje datoteka,

- Arhivsko uređivanje - baza podataka/informacija je uređena na prihvatljiv način i razumljiva za korisnika. Potrebno je minimalno tehničko znanje da bi se informacija mogla naći brzo, bilo gde i bilo kada,

- Figurativnost - prikazivanje motiva iz realnog vidljivog sveta u virtualni,

Pored toga, Lejla Turčilo[10] u kontekst tehničkih i organizacionih karakteristika dodaje i:

- Decentralizovana struktura - ne postoji nikakva centralna organizacija koja bi kontrolisala događanjima na internetu,

- Nepregledna količina informacija - sve informacije na internetu su dostupne svim korisnicima,

- Orjentisanost na korisnika - sve aktivnosti na internetu su u službi korisniku. Autor Turčilo na ovo dodaje još i sledeće karakteristike interneta kao što su: globalna dostupnost, komunikabilnost, jednostavnost, neograničenost i ravnopravnost.

Spomenimo još jedno relevantno svojstvo intereneta koje navodi Christina Holtz-Bacha [11], a reč je o:

- Konvergentnost - radi se o međusobnom prožimanju i spajanju tradicionalnih načina informisanja u jednu online informaciju. Na primer tekstualni sadržaji se oplemenjuju sa drugim izražajnim sredstvima.

Naravno, ovde smo istakli samo tehničke i funkcionalne dimenzije pojma internet, što sigurno nije i dovoljno da se razume njegova suština. Jer, ne može se govoriti o internetu kao o "izumu" izvan svrhe i namene.[32] U tom smislu prof. Štambuk (1999) u svojoj knjizi "Internet i politika" kaže: "Nastanak i delovanje zajednica korisnika interneta predstavlja značajnu kulturnu i civilizacijsku inovaciju".[12] Pri tome internet je novi medij, koji funkcioniše kao jedna homogena celina, koja ima svoja sopstvena svojstva i zadatke ali i meta medij koji objedinjuje i druge medije(tekst, slika zvuk). Na internetu nema posrednika izme- 
đu pojedinca koji izražava mišljenje i medija tj interneta. Svako može da bude prisutan bez tehničkog znanja i bez ograničenja.[13] Pružanje mogućnosti da se svaki pojedinac uključi, ali i izađe iz neke zajednice ljudi koji međusobno redovno komuniciraju pomoću interneta, daje internetu ne samo demokratske, već i sasvim nove kvalitete komunikacije, ali i karakteristike međuljudskih odnosa. Pri tome, kako tehnološke mogućnosti rastu, tako rastu i demokratski procesi za glasanja, participaciju u upravljanju, mogućnosti obrazovanja i dogovaranja, a to je način da se podstakne uključivanje u demokratske procese, da se stvori klima političke jednakosti i spreči bilo kakav pokušaj tiranije. Korišćenje interneta u političkoj komunikaciji je imperativ demokratskog društva, jer u internetu se vidi mogućnost da građani u političkoj igri ne ostanu samo navijači, nego da postanu i saigrači. To ni jedan medij ne omogućava i zato njegovu široku lepezu mogućnosti treba prepoznati i iskoristiti ih.[10]

\section{Političke aktivnosti na internetu}

Političari i političke stranke su vrlo brzo prepoznale da se sva politička komunikacija koja je do sada tekla putem klasičnih (mas)medija može odvijati i putem interneta i da im njegovi alati omogućavaju da dođu do glasačkog tela do kojeg možda ranije nisu imali efikasnog pristupa. Prošla su vremena u kojima mali čovek iz naroda mora da čeka četiri godine da bi mogao da utiče na vlast, što bi opet činio samo činom izlaska na izbore nakon čega bi se vraćao apsolutnoj pasivnosti.

Naročito je na intenziviranje političkih aktivnosti uticao brzi porast broja korisnika zadnjih godina. Što se broj korisnika interneta povećavao sve je više bilo organizacija koje su želele da se na njemu pojave, jer je bilo sve više potencijalnih primalaca poruka. I ne samo to, došlo je i do nastanka novih političkih organizacija koje pre ere interneta nisu ni postojale. Već sada se može reći da ni jedna politička organizacija koja sebe smatra za ozbiljnu nije mimoišla internet kao medij za svoju promociju.

Ne može se dovoljno naglasiti značaj i mogućnosti da se poruka, bilo članovima, bilo podržavaocima neke organizacije prenese pouzdano i brzo. Prakse koje deluju već dugo vremena, kao što su okružne organizacije postale su zastarele kada ih uporedimo sa diskusionim listama, prenošenjem poruka i dostavom informacija preko www. Zbog toga što se komunikacija na mreži odvija skoro trenutno (gotovo u realnom vremenu), događaji zanimljivi grupi koji se dešavaju u jednom delu sveta mogu se preneti grupi na drugom delu sveta skoro istog trenutka.[12]

Internet u velikoj meri ukida masovnost i uvodi individualne kontakte kao bitne političke procese. Internet pruža mogućnost individualnog neposrednog kontakta između kandidata i birača. I najneznačajnija osoba, i najmanja web strana, može dobiti publicitet, može da se čuje.

Internet omogućava svakome da se ravnopravno bori sa protivkandidatima pod jednakim uslovima. Ključ uspeha nije više posedovanje ogromne infrastrukture ili finansijske podrške, nego originalne ideje i kvalitet sadržaja.[14]

Za neke grupe internet je jedini medij putem koga one mogu da se organizuju. Zbog ograničenja vremena i udaljenosti, grupe sa malo članova, i to udaljenih, koje u prošlosti nikada nisu ni mogle postojati, sada su postale stvarne organizacije. I kada internetom njihovi članovi jednom pronađu jedni druge, oni naravno mogu postati snaga u političkom svetu, jer mogu komunicirati sa ostalim grupama sličnih interesovanja i mogu komunicirati sa svojim zakonodavcima i sa vladom u svojim naporima da uspostave svoju poziciju. 
Internet pomaže mnogim organizacijama da na lak način sakupe osnovne informacije sa imenima i mogućnostima kontakta, radi regrutovanja novih članova ili simpatizera.

Činjenica je da postoje neke teškoće u sakupljanju sredstava preko internet platforme, ali one nisu nepremostive. Kada će političke grupe raditi na izborima u neposrednoj budućnosti, mogućnost mikro uplata i ekvivalent elektronskom kešu za transfer sredstava učiniće i političko sakupljanje sredstava znatno lakšim nego što je ono sada. To znači da će političke grupe umnogome koristiti sve one benefite svojstvenim elektronskom poslovanju.

Kada internet korisnici koji su stalno prisutni na njemu određene sadržaje smatraju zanimljivim i privlačnim, tada se kod njih mogu stvoriti određene navike koje se mogu ustaliti. Tako na primer, kada korisnici interneta otkriju da web sajt neke od političkih partija daje pouzdane i precizne informacije o pitanjima koje njih zanimaju, onda će se oni stalno vraćati na taj sajt, odnosno stvaraće navike koje se mogu ustaliti, što će im vremenom pomoći da i samu partiju definišu kao pouzdanu i preciznu i da budu bliže identifikaciji sa samom partijom.

Internet je omogućio da ga novinski mediji u velikoj meri koriste. Taj trend se sigurno neće promeniti. Zapravo on će najverovatnije postati još izraženiji kako medijska sredstva budu ulazila u sve veću konkurenciju za osvajanje medijskog tržišta, koje u sve većoj meri postaje diferencirano kako se pojavljuju novi vidovi kablovske televizije, a web sajtovi počinju da se smatraju sve više kao legitimno sredstvo komunikacije. U tom smislu, mnoge organizacije sve više prihvataju da je jedan od najsigurnijih načina za dobijanje medijske pažnje, putem mreža.

Komunikacija sa potencijalnim glasačima putem interneta naročito pogoduje manjim strankama, jer ih stavlja u ravnopravan položaj sa kandidatima iza kojih stoje velike partije i mnogo novca.[15] Pored toga često manje političke organizacije i stranke pokazuju veću efikasnost pri nametanju svojih ideja od onih većih, pa i nacionalnih. To je i logično, zbog izvesne tromosti i inertnosti koja prati one mnogobrojnije i više institucionalno okoštale partije.

Između vlade i građana postoji stalan odnos i potreba da se intenzivno komunicira. Svi dosadašnji sistemi komunikacije bili su spori i jednosmerni tako da su mogućnosti građana da direktno komuniciraju sa vladom bili ograničeni. Lakša i brža komunikacija sa političkom elitom, upravom lokalne zajednice i države, kada se odlučuje o nekim egzistencijalnim pitanjima, u svakom slučaju pridonosi zadovoljstvu građana.

$\mathrm{U}$ vremenima kada je migracija stanovnika svakodnevna pojava interneta omogućava onima koji su otišli da učestvuju u procesima u zemlji matici što predstavlja njihovu direktnu vezu sa njom. Putem internet veza oni mogu efektivno i produktivno da se uključe u proces razvoja svoje zemlje porekla, bez nekog privremenog ili trajnog fizičkog povratka.

Internet je izazvao dalekosežne efekte i na karakter međunarodnih odnosa, omogućivši decentralizaciju i zaobilaženje birokratskih struktura. Internet je stvorio globalnu zajednicu. U takvoj zajednici raste dostupnost informacija o događajima u stranim zemljama kao i neposredni nacionalni kontakti ne samo između država, nego i drugih vladinih tela, međunarodnih i domaćih, nevladinih i privatnih humanitarnih.

\section{Internet u političkoj komunikaciji - korišćenje interneta od strane stranaka, kandidata i birača}

Zbog svojih svojstava, upotreba interneta sve je raširenija u svetu, i brojna istraživanja se slažu da se internet u visokorazvijenim zemljama sve češće koristi i u političkoj komunikaciji. Kao što je prestanak masovne proizvodnje najavio kraj klasične industrijske 
ere, tako je i internet najavio potrebu za bitnim promenama u političkom životu, a pre svega u delovanju političkih stranaka. Zahvaljujući, vrtoglavom usponu interneta i društvenih mreža, jedan od ključnih kanala političkog marketinga preselio se na web. Internet je sada postao nezaobilazan alat u političkoj komunikaciji i nezamislivo je voditi kampanju bez iskorišćavanja njegovih prednosti. Međutim, istraživanja ukazuju na razlike u pogledu uloge interneta u SAD i u Evropi. [16]

Od 1966. godine kada su sprovedeni izbori u SAD publikovano je više naučnih radova i tekstova u medijima na temu o političkoj komunikaciji putem interneta. Generalno iz svih njih proističe zajednička konstatacija da političari sve više koriste internet i da danas gotovo da nema političara koji ne koristi neke njegove alate. Zanimljivo je istaći da je za vreme predsedničkih izbora 2008 . godine $40 \%$ građana koristilo pretraživanje na internetu radi informisanja o kandidatima i programima stranaka, zatim $25 \%$ građana bilo je jednom nedeljno na stranicama političkih stranaka kako bi saznali značajne podatke o predsedničkoj kampanji i 10\% građana je koristilo elektronsku poštu kako bi učestvovali u raznim političkim debatama.[17]

Tokom kampanje za predsedničke izbore 2012. godine Hilari Clintton, Barack Obama i Johan Edvards predsednički kandidati američke Demokratske stranke nagovestili su svoje kandidature putem blogova. Ono što ovu kampanju diferencira od ostalih jeste prvenstveno početna postavka u kojoj su sami birači stavljeni u prvi plan - bili su uključeni u kampanju upravo putem društvenih mreža (Facebook, Twiter, You Tube i razni blogovi) i time postali svojevrsni saradnici u kampaniji. Koliko je internet za Obamu bio bitan pokazuje istraživanje centra Pew Research koje je pokazalo da je čak četvrtina korisnika društvenih medija koji su imali kontakt sa političkim temama vezanim za izbore i debate online postala aktivnija u izbornom procesu, iznoseći mišljenja i deleći sadržaje. Čak je $16 \%$ birača promenilo mišljenje o tome za koga će glasati zahvaljujući onome što su videli na internetu.[15] Osim toga, Obama je tokom ove kampanje prikupljao i tzv. mikro donacije i odbijao uobičajene milionske donacije velikih korporacija. Ovim potezom dodatno je privukao poverenje birača. Zanimljiv je podatak da je u samu onlajn kampanju bilo uloženo 24.185.965 dok je ovim mikro donacijama prikupljeno više od 500 miliona dolara. Što se tiče njegove baze fanova, nakon kampanje Obamina Facebook stranica je brojala 5.006.446 fanova.[18] Kakvu je ulogu imao internet u vreme američkih predsedničkih izbora iz 2016. godine, govori i broj pretraživanja odrednice "kako da glasamo" na Guglu u periodu od 1. oktobra do 1. novembra koji je tada porastao za 233 odsto u odnosu na američke predsedničke izbore 2012. godine.

Kada je reč o evropskim istraživanjima uočljivo je da uticaj interneta na informisanje odnosno formiranje preferencije birača, odnosno na rezultat izbora znatno manji nego što se na privi pogled misli i piše u medijima. Grupa danskih istraživača analizirala je ulogu interneta u predizbornoj kampanji za nacionalni parlament (Folketing) 2005. godine i došla je do iznenađujućih zaključaka. Istraživanje je pokazalo da je 23\% birača (Danska ima oko 5,5 miliona stanovnika) posetilo neki stranački sajt najmanje jednom u toku predizborne kampanje. Još apsurdnijim pokazuje se mit o velikom značaju interneta kada se analizira posećenost stranačkih sajtova. Tokom kampanje taj broj je varirao od 2-8 hiljada dnevno (uz velike varijacije po strankama). Na zadnji dan kampanje brojevi su porasli na 10-15 hiljada. Dnevni prosek je bio 5 hiljada. Interesantan je i podatak da su na primer pisma čitalaca koja nose političku poruku stranke u samo jednim novinama doprla do najmanje 20 puta više lju- 
di nego stranački sajtovi na internetu. Dalje u spomenutom istraživanju samo $19 \%$ ispitanika smatra da im je poseta na stranačke sajtove u većoj ili manjoj meri pomogla u konačnoj odluci za koga će glasati. Čak $62 \%$ smatra da to nije imalo nikakvog uticaja na njihov izbor. Isto istraživanje otkriva da je internet bio ocenjen kao najbolje mesto da se nešto sazna o stranačkoj politici od svega $3,5 \%$ ispitanika. Istovremeno je $27 \%$ tu ocenu dalo završnim TV sučeljavanjima, a čitavih $47 \%$ TV dnevnicima.[19]

Jedno drugo istraživanje u vezi saveznih izbora u Nemačkoj 2002. godine pokazuje da je nakon ovih izbora tek $6 \%$ birača ocenilo internet kao najvažniji izvor značajnih informacija.[20] Ono što je zanimljivo je da su za izbore za Bundestag održanim 2013 godine na 8000 biračkih mesta isključivo korišćeni tradicionalni glasački listići i da nije upotrebljen ni jedan glasački uređaj. Dalje, istraživanje koju su sproveli: Oliver Falck, Robert Gold, Stephan Heblich, 2012. godine vezano za lokalne izbore ukazalo je da su se na rang listi od 11 komunikacionih kanala - od letaka dostavljenih po kućama do nacionalnih novina, internet našao na poslednje mesto.[21] Nemačko istraživanje razotkriva da su birači sa čvrstom stranačkom opredeljenošću ti koji traže informacije na internetu. Zato je potencijal "selidbe" glasova putem interneta gotovo zanemarljiv, ali nasuprot tome, internet, odnosno stranački sajtovi se pokazuju kao izvanredno sredstvo komunikacije stranaka s vlastitim simpatizerima.

Bebić Damagoj (2009) u jednom svom istraživanju ukazuje da su stranke u Hrvatskoj na parlamentarnim izborima 2007. godine samo delimično iskoristili marketinški potencijal interneta. Posebno su podbacile male stranke koje su propustile barem u online svetu da premoste jaz između sebe i velikih stranaka. Analizom elemenata interaktivnosti Bebić je pokazao da stranke u predizborno vreme u načelu nisu koristile internet kako bi se upustile u raspravu sa biračima.[22]

U kratkom sižeu prethodnih rezultata istraživanja može se zaključiti da upotreba interneta u svrhu rasprave sa strankama i kandidatima, koja ima za cilj povećanje opšte uključenosti građana i mreže kruga političkih aktivnosti građana, nije ispunila očekivana predviđanja.

Ako želimo sagledati i kakva je uloga interneta u dvosmernoj komunikaciji odnosno ostvarenja dijaloga i političke komunikacije uočiće se da i američka i evropska istraživanja pokazuju da iako su političke stranke prihvatile platformu interneta kao sredstva komunikacije, one još uvek nisu dovoljno razvile njegov potencijal za ostvarivanje dvosmerne komunikacije odnosno ostvarenje dijaloga i političke participacije građana. Dakle, bez obzira što internet poseduje važno svojstvo interaktivnosti ono se slabo koristi kao sredstvo komunikacije sa građanima u političkim kampanjama. Na primer, zapaža se da se i za vreme izbora na internetskim stranicama kandidata za američki Kongres teško može naći prostor namenjen raspravi birača s kandidatima ili članovima izbornih timova.[23]

Kad je reč i o Srbiji, dolazi se do sličnih saznanja kao i za strana. SHARO Fondacija [24] je tokom izbornih kampanja za vanredne parlamentarne izbore 2016. godine i predsedničke izbore 2017. godine u Srbiji propratila aktivnosti političkih aktera na društvenim mrežama. U tom smislu, SHARO Fondacija se fokusirala na zvanične fejsbuk stranice 22 političke stranke koje su učestvovale na parlamentarnim izborima 2016. godine i 11 stranica predsedničkih kandidata (2017. godina). Istraživanjem se želelo da utvrdi broj individualnih korisnika koji su ulazili u interakciju sa Fejsbuk objavama političkih aktera, kao i broj njihovih interakcija (lajkova i komentara) iz nedelje u nedelju tokom kampanje (7 nedelja za parlamentarne i 6 nedelja za predsedničke). Na slici 1 može se videti da kako se dan glasanja približavao (24 april), tako su interakcije na fejsbuku rasle uzlaznom putanjom. 


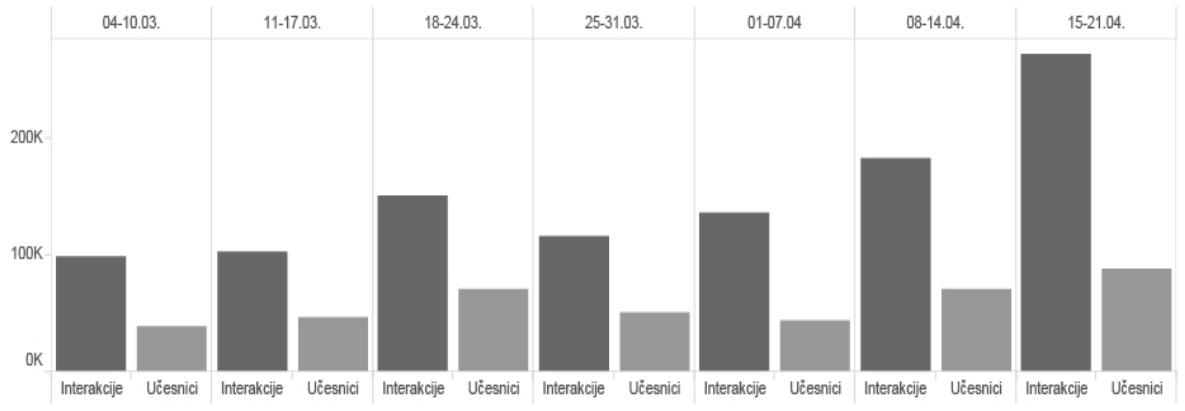

Slika 1 - Broj interakcija po nedeljama - Parlamentarni izbori 2016.

Izvor: https://labs.rs/sr/onlajn-izborna-kampanja-u-srbiji/

U predsedničkoj kampanji 2017. godine zenit je bio nedelja kada je isticao rok za predaju potpisa za kandidate 9-15 marta.

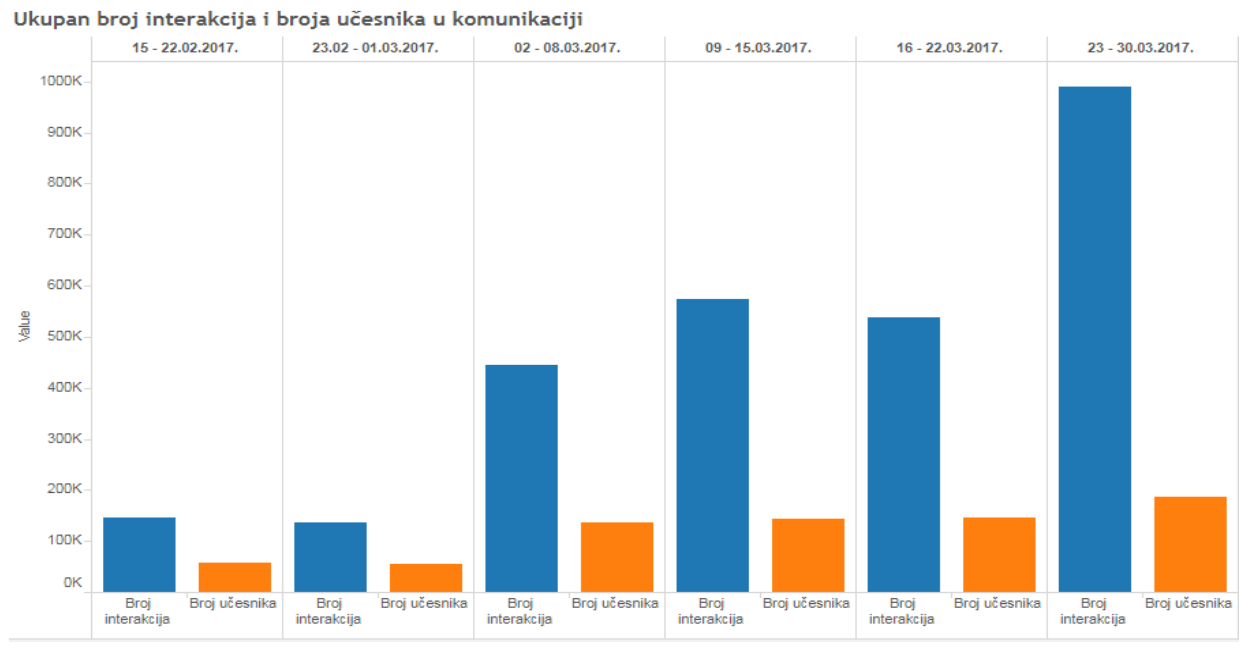

Slika 2 - Interakcije po nedeljama - Predsednički izbori 2017.

Izvor: https://labs.rs/sr/onlajn-izborna-kampanja-u-srbiji/

Kada se porede metrike dve kampanje na Fejsbuku, zabeležen je značajan porast aktivnosti tokom kampanje za predsedničke izbore. Naime, nešto manje od 200.000 korisnika su ostvarili interakcije sa zvaničnim stranicama partija tokom kampanje 2016. godine, dok je predizborna kampanja za predsedničke izbore privukla znatno više građana zainteresovanih za političke sadržaje na Fejsbuku, reč je čak 330.000 naloga koje je softver registrovao tokom istraživanja. Dalje, interesantno je da su interakcije za vreme predsedničke kampanje dostigle još veći rast - za šest nedelja kampanje ostvareno je više od 2,8 miliona interakcija u poređenju sa oko milion interakcija tokom izbora za narodne poslanike 2016. godine. 
U vreme predizborne kampanje za predsedničke izbore 2016. godine, Istraživači SHARO Fondacije su uradili i analizu komunikacije političkih aktera na Tviteru. Prema rezultatima istraživanja stranke su objavljivale najviše tvitova za vreme kampanje, ali se kod njih primećuje da je u većini slučajeva slično kao na Fejsbuku, reč je samo o jednosmernim saopštenjima, dakle, bez uključivanja drugih korisnika u tvitove i bez pružanja odgovora. Osim toga, stranke su imale i različite pristupe tempiranju kampanje na Tviteru. Registrovana je i velika polarizacija domaće Tviter - sfere za vreme izborne kampanje, kao i da su „haštagovi“ bili izuzetno korišćeni tokom kampanje. Dakle, uzimajući u obzir analize u obzir dve kampanje, jednu stranačku i jednu kandidatsku, jasno se vidi da političke stranke nisu koristile alate interneta kako bi ostvarile dvosmernu komunikaciju s biračima a i da bi ojačale veze sa članstvom stranke. Drugim rečima stranke nisu dovoljno uvidele potencijal koji pružaju društvene mreže. Društvene mreže koriste se tek kao sredstvo dodatnog oglašavanja, a ne kao sredstvo dvosmerne komunikacije. Njihova komunikacija sa potencijalnim biračima na društvenim mrežama se svodi na period tokom predizbornih kampanja, bez interaktivnosti i sa jednosmernim pristupom - ne postoji dodatno animiranje birača kroz zanimljiv content gde bi se mogla čuti različita mišljenja i dodatno podstakla deliberacija o važnim pitanjima i problemima.

Kada je reč o kampanji za izbore maja 2012. godine u Vojvodini, stranka Saveza vojvođanskih mađara (SVM) koristila je sve moguće kanale za promociju svojih ljudi i ideja: Fejsbuk, blogove, internet prezentacije, Jutub, njuzletrs-ali očigledno ne na naročito efikasan način. O tome svedoči slaba interaktivnost, malo komentara, "lajkova" i fanova na pojedinim stranicama. Stranka SVM nije najefektivnije koristila internet alate kako bi se upustila u raspravu sa biračima niti da bi ojačala veze među stranačkim članovima. Znači, iako je internet prepoznat kao sredstvo promocije, on nije adekvatno korišćen za dvosmernu komunikaciju sa biračima, odnosno da korisnik postane ravnopravan učesnik u komunikacionom procesu.

Po rečima Predraga Haramije[16] najčešće postavljeno pitanje u brojnim istraživanjima je da li neka stranka ili kandidat koristi efikasnije internet od drugih i zašto. Pri tome osnovni cilj tih istraživanja je kako pronaći najbolji način da bi se efektivnije koristio internet, koji u svojoj biti sadrži uticaj kampanje putem interneta na rezultate izbora, a manje kao uticaj takve kampanje na društvo u smislu značajnijeg učešća građana na izborima.

$\mathrm{U}$ tom smislu različita istraživanja govore da danas još uvek mali broj birača posećuje mrežnu stranicu nekog kandidata, i da vrlo mali broj birača smatra relevantnom pri donošenju odluke, što sve navodi na zaključak da internet onako kako su ga koristili kandidati na izborima nema bitan uticaj na rezultate izbora. Postavlja se onda pitanje kako bi trebalo koristiti internet u izbornoj kampanji a da bi njegovo korišćenje bilo efektivno? Odgovor na to pitanje nema sumnje treba potražiti u samoj suštini interneta odnosno njegovim bitnim svojstvima. Naime, alati interneta za političke stranke predstavljaju idealne mehanizme za direktno povezivanje sa potencijalnim glasačima i njihovo angažovanje koje bi kroz tradicionalni okvir (tzv. terenske kampanje) bilo nemoguće. Radi se, naime, prvenstveno u tome da je internet idealno sredstvo kojim stranke mogu mobilisati svoje članstvo i simpatizere kako bi učestvovali i aktivno sprovodili izborne kampanje u realnom okruženju. Shodno tome, važna je unutar stranačka komunikacija, jer ako stranke u tome uspeju, i izborne kampanje i njihovi rezultati biće bolji.[25] Po mišljenju jedne grupe autora: Oliver Falck, Robert Gold, Stephan Helich, birači sa čvrstom stranačkom opredeljenošću su ti koji traže informacije na internetu.[26] Iz tih razloga i internet sa svojim alatima se pokazuje kao izvanredno sredstvo komunikacije stranaka sa svojim pristalicama. U 
SAD se ova strategija pokazuje vrlo jasnom gde i u najjačim strankama članstvo nije brojno, ali u kojima većina zna da bude u ulozi volontera i pomagača u kampanji. Tako je u kampanji Baraka Obame na predsedničkim izborima u Americi učestvovalo miliona volontera, koji su zakucali na 10 miliona vrata. Osim toga, Obamin marketinški tim koji se bavio nastupom na društvenim mrežama akcenat je stavio na kvalitet kreiranog sadržaja (content). Angažovanjem tada 24-godišnjeg Krisa Hjuza, suosnivača Fejzbuka, koji je bio zadužen za kreiranje onlajn marketinške arhitekture zauvek je promenjen pristup jednog političara i političke stranke na društvenim mrežama. U tom kontekstu kvalitetan content je podrazumevao kreiranje sadržaja koji će angažovati korisnike društvenih mreža sa ciljem da se što više njih uključi u rad i da potencijalni birači postanu najbolji partneri sa mnoštvom saveta, ali i akteri koji će raditi ono najvažnije - širenje ideje. Tako da nakon pobede Baraka Obame, onlajn komunikacija postaje veoma zastupljena u političkoj komunikaciji, jer je Obama iskoristio sve prednosti interneta i uključio ga u sve segmente političke kampanje. Zato i ne iznenađuje što i u zapadnoj Evropi ima sve više ovakvih primera da se stranke u pripremi kampanje koriste internetom na takav način.[27]

Međutim, iako su političke stranke vrlo brzo prihvatile internet kao sredstvo komunikacije one još nisu razvile njegove potencijale po pitanju koristi za vođenje rasprave, odnosno radi povećanja političke participacije građana. Sa tim u vezi autor Vard i dr. ističu da internet, osim što povećava učinak mobilizacije pristalica i simulira izbornu participaciju on i stvara nove virtuelne mreže pristalica, kao i povećava mogućnost pluralizma u organizaciji, uopšte omogućava nove oblike učešća i olakšava jednakost učešća.[28]

Pitanje koristi političke uloge interneta odnosno participacije građana u političkom životu, odnosno da li internet menja tradicionalne oblike političkog delovanja i načina na koji pojedinci razumeju politiku našlo se u fokusu istraživanja Endrju Čedvika (Andrew Chadwick) sprovedenog, pre svega u okviru Oksfordskog Internet politika (Internet Politics) 2006. godine. Čedvik je, analizirao upotrebu Interneta u politici u SAD i Velikoj Britaniji. Po Čedviku internet omogućava stvaranje i delovanje političkih grupa i pokreta, nezavisno od prostora i vremena.[29] Čedvik u jednom svom drugom delu ističe da je ključno pitanje: da li se i na koji način sa pojavom novih informacionih tehnologija promenio i način upravljanja aktivnostima raznih zajednica i organizacija građana i kako te zajednice koriste internet kao dodatak svojim akcijama u realnom svetu, i posebno kako ga koriste za prikupljanje sredstava i regrutovanje novih pristalica što se posebno odnosi na političke partije.[30]

Srećna je okolnost što ima dosta primera i u Svetu da razna udruženja putem interneta mobilišu građane oko nekog društvenog ili političkog pitanja. Međutim, ima malo primera da to čine političke stranke. Rezultati nekih istraživanja kod nas [31] govore da političke stranke iako koriste pojedine internet alate, na prvom mestu sajtove, a po nekad i određene društvene mreže, ali upotreba interneta kao sredstva dijaloga, rasprave stranaka i kandidata sa građanima i, posledično, širenje kruga politički aktivnih građana nije razvijena. Političke stranke uglavnom poseduju jednolične i statične web sajtove. To je zapravo $99 \%$ njihovih onlajn aktivnosti. Sajtovi ne dozvoljavaju interakciju sa posetiocima, a aktivnosti su dinamičke tek oko izbora. Nekorišćenje interneta kao sredstva dijaloga (dvosmerne komunikacije) u politici rezultat je: Prvo što stranke i njihovi javni zastupnici ne razumeju ovaj medij i nužnosti uspostavljanja višesmerne komunikacije u procesu kreiranja demokratskog javnog dijaloga. Drugo što javni zastupnici stranaka razumeju internet kao medij ali nemaju podršku od rukovodstva stranke za vođenje i upravljanje dijalogom kakav ovaj medij zahteva. 


\section{Svojstva političke komunikacije putem interneta na primeru grada Niša}

Internet platforma može imati neki uticaj na biračke preferencije, ako su obezbeđeni preduslovi da je kandidati i političke stranke koriste na odgovarajući način, ali i da je građani koriste kao izvor informacija o kandidatima. U tom smislu, sprovedeno je istraživanje kojim se želelo ispitati: prvo da se sagleda način kako kandidati za gradonačelnika Niša koriste internet, a zatim da se kroz anketu koja je sprovedena među građanima grada Niša, sazna u kojoj meri građani Niša koriste internet platformu za predsedničke i parlamentarne izbore. Za istraživanje izabran je grad Niš, jer je to drugi grad po veličini u Srbiji, koji ima tradiciju-elektronska industrija (EI Niš), grad koji ima svoj univerzitet i u kome danas živi brojna populacija koja se služi internetom, pa su u tom smislu i razlozi za upotrebu interneta kao sredstva izborne kampanje utoliko značajni.

Kao što je već istaknuto namera je bila da se istraži da li su u predizbornoj kampanji za gradonačelnika Niša kandidati imali svoje mrežne stranice, kojim su se društvenim mrežama služili i na koji način. Našim istraživanjem, dobijena je informacija da kandidati u celini nisu bili prisutni u predizbornoj kampanji na internetu, odnosno kandidati nisu imali svoju mrežnu stranicu. Pokazalo se da kandidati za gradonačelnika nisu koristili komunikacije sa članovima svojih stranaka, niti sa simpatizerima, a da ne govorimo sa širim krugom građana. Shodno tome ukupan broj osvojenih glasova na izborima bio je posledica napora odnosno korišćenja ostalih sredstava u kampanji (odnosno autoriteta kandidata), a ne nikako korišćenjem interneta. Dakle, gledano sa aspekta učinka, može se reći da kandidati za gradonačelnika grada Niša nisu znali da iskoriste potencijal platforme interneta u komunikaciji sa svojim strankama, simpatizerima i širim grupama građana.

Dalje, namera je bila da se u okviru istraživanja sazna i u kojoj meri građani Niša koriste internet kao sredstvo informisanja o strankama i kandidatima za vreme predsedničkih i parlamentarnih izbora, $U$ tom smislu, u vremenu od 20.01.2019. do 19.02.2019. sprovedena je anketa na uzorku od 191 ispitanika. Uzorak ispitanih birača grada Niša podeljen je tako da približno ravnomerno predstavi oba pola (96 muški i 95 ženski) i da relativno ravnomerno predstavi po starosnim grupama kako ih često dele istraživanja učestalosti upotrebe interneta, 58 ispitanika starosti od 18 do 25 godina (najučestaliji korisnici interneta), 67 starosti od 26 do 40 godina (učestali korisnici interneta) i 66 starosti od 40 i više godina (povremeni korisnici ili ne korisnici interneta). U tom smislu, da bi se obuhvatili i korisnici i ne korisnici interneta anketni list je rađen na papiru.

Prvo anketno pitanje bilo je: Koje je od navedenih sredstava informisanja najviše uticalo na vaš stav o tome za koga ćete glasati na prošlim izborima za predsedničke i parlamentarne izbore? (Televizija, Radio, Novine i časopisi; Plakati; Internet; Razgovor sa porodicom i prijateljima) U vezi sa postavljenim anketnim pitanjem dobijeni su sledeći rezultati: 


\begin{tabular}{|c|c|c|c|c|c|c|c|c|}
\hline & \multicolumn{2}{|c|}{$\begin{array}{c}\text { Starosti } \\
18-25 \\
\\
58\end{array}$} & \multicolumn{2}{|c|}{$\begin{array}{c}\text { Starosti } \\
26-40 \\
67\end{array}$} & \multicolumn{2}{|c|}{$\begin{array}{c}\text { Starosti } \\
40 \text { i više } \\
66\end{array}$} & \multicolumn{2}{|c|}{$\begin{array}{c}\text { Ukupno } \\
191\end{array}$} \\
\hline & B & $\mathbf{P}$ & B & $\mathbf{P}$ & B & $\mathbf{P}$ & B & $\mathbf{P}$ \\
\hline Razgovor & 14 & 24,1 & 21 & 31,3 & 29 & 43,9 & 64 & 33,5 \\
\hline Televizija & 11 & 18,9 & 14 & 20,8 & 15 & 22,7 & 40 & 20,9 \\
\hline Novine,časopisi & 0 & 0 & 6 & 8,9 & 8 & 12,1 & 14 & 7,3 \\
\hline Internet & 30 & 51,7 & 22 & 22,8 & 10 & 15,1 & 60 & 32,4 \\
\hline Radio & 1 & 1,7 & 2 & 2,9 & 1 & 1,5 & 4 & 2,0 \\
\hline Plakati & 2 & 3,4 & 2 & 2,9 & 3 & 1,5 & 7 & 3,6 \\
\hline Leci & 0 & 0 & 0 & 0 & 0 & 0 & 0 & 0 \\
\hline
\end{tabular}

B - Broj onih koji su se izjasnili,

P - Procenat onih koji su se izjasnili

Drugo anketno pitanje bilo je: Da li ste možda tokom izborne kampanje posetili mrežnu stranicu neke stranke ili kandidata? Odgovori su bili sledeći:

\begin{tabular}{|l|r|r|r|r|r|r|r|r|}
\cline { 2 - 9 } \multicolumn{1}{c|}{} & \multicolumn{2}{c|}{$\begin{array}{c}\text { Starost } \\
18-25\end{array}$} & \multicolumn{2}{c|}{$\begin{array}{c}\text { Starost } \\
26-40\end{array}$} & \multicolumn{2}{c|}{$\begin{array}{c}\text { Starost } \\
\text { 40 i više }\end{array}$} & \multicolumn{2}{c|}{ Ukupno } \\
\hline & B & \multicolumn{1}{c|}{ P } & B & P & B & P & B & P \\
\hline Da & 5 & $21,7 \%$ & 18 & $24,3 \%$ & 19 & $22,6 \%$ & 42 & $22 \%$ \\
\hline $\mathrm{Ne}$ & 18 & $78,2 \%$ & 56 & $75,7 \%$ & 65 & $77,4 \%$ & 149 & $78 \%$ \\
\hline
\end{tabular}

B - Broj onih koji su se izjasnili,

$\mathbf{P}$ - Procenat onih koji su se izjasnili

Uočljivo je da internet na ovim izborima nije bilo najznačajnije sredstvo informisanja o političkim strankama i kandidatima. Internet je za oko $32,4 \%$ anketiranih uticao pri donošenju odluke o glasanju. Internet je na drugom mestu po važnosti, nalazi se iza razgovora sa porodicom i prijateljima 33,5\%. Međutim, taj se broj razlikuje zavisno od starosti; u najstarijoj starosnoj grupi (od 40 godina i naviše) on je još manji 15,1\%, ali je u najmlađoj starosnoj grupi (od 18-25 godina) on znatno veći 51,7\%. Tako da se može zaključiti da će sa prirodnim demografskim promenama taj broj samo rasti. Ako se uzme u obzir dinamično povećanje broja korisnika interneta, treba očekivati da će već za par godina znatno više birača koristiti internet kao sredstvo informisanja o važnim pitanjima za donošenje odluke o glasanju. Naravno, to će se ostvariti samo ako stranke i kandidati razviju takav sistem komunikacije na internetu koji će im biti privlačan, tj. ako razviju dvosmerne komunikacije. 


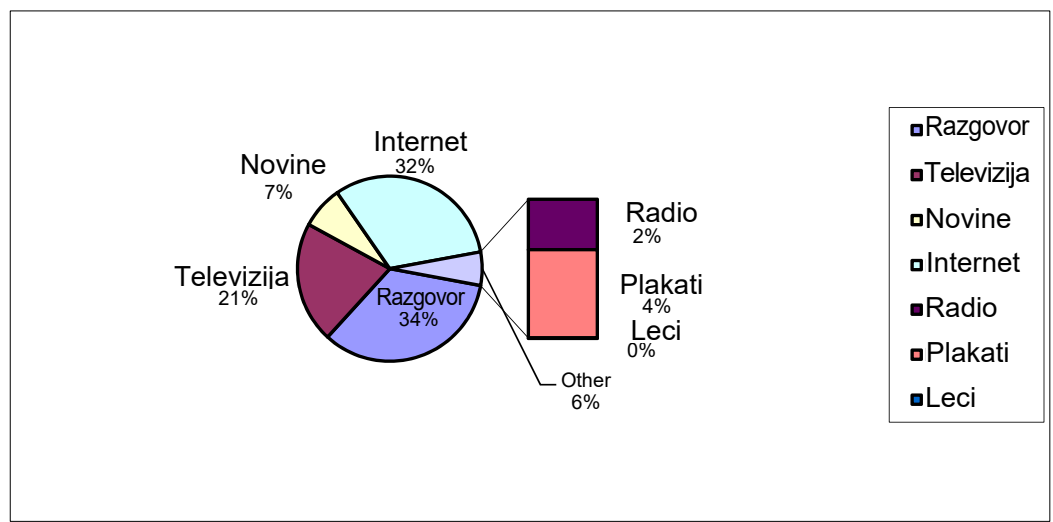

Grafik 1 - Učešće pojedinih sredstava informisanja pri donošenju odluke o glasanju za političke stranke $i$ kandidate

Važno je istaći i činjenicu, da nezavisno od starosti ispitanika, broj onih koji kao najvažnije za donošenje odluke o glasanju smatraju razgovor sa porodicom i prijateljima (prelazi $20 \%$ ). Znači, lični ljudski kontakt sa bliskim osobama kojima se veruje i dalje će ostati ne malo važnim za donošenje odluke o glasanju. U vremenu globalizacije, materijalima i sistemskog napada na porodične vrednosti to unosi dašak optimizma. Istovremeno to ukazuje i na važnost iskrenosti i verodostojnosti u komunikaciji. Dakle, ako političari svojim biračima priđu sa poštovanjem, kao prijateljima i pri tom budu iskreni, verodostojni, možda će im se više i verovati.

Dalje, zanimljivo je uočiti i relevantnu važnost televizije koja je sa 20,9\% ukupno na trećem mestu. Uočljivo je da novine i časopisi za mladu generaciju (18-25) nemaju nikakav značaj, za donošenje odluke o glasanju, dok za srednju $(8,9 \%)$ i stariju $(12,1 \%)$. Shodno tome, može se konstatovati da će uticaj pisanih medija na izbore smanjivati kako "internet generacija", znači bude starila to jest bude se povećavao uticaj internet mreže.

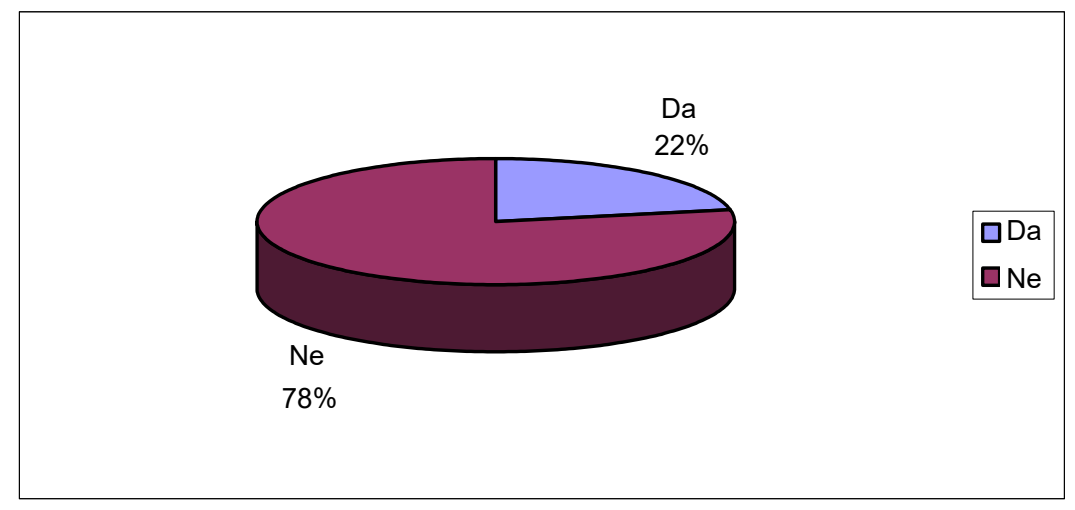

Grafikon 2 - Struktura koliko su građani tokom izborne kampanje posetili mrežnu stranicu neke stranke ili kandidata 
Imajući u vidu prethodno rečeno možda bi ovde trebalo postaviti i jedno važno pitanje. Kada se vidi da je $22 \%$ anketiranih uopšte posetilo mrežnu stranicu nekog kandidata na izborima, može se zaključiti da se upotreba interneta mnogo ne isplati. Međutim, treba očekivati da će se vremenom ovakvo stanje promeniti, jer podaci pokazuju da je u najmlađoj starosnoj grupi $21,7 \%$ anketiranih posetilo mrežnu stranicu nekog izbornog kandidata. Dakle, ako kandidati ili stranke žele pridobiti glasove mlade populacije one moraju i da ulažu u svoje mrežne stranice. Pri tome naročito je važno da se te mrežne stranice koriste kao sredstvo dvosmerne komunikacije, kao sredstvo dijaloga i to tako da je mnogo važno za kandidate i stranke da pažnju obrate na "osluškivanje a ne na uveravanje".[16] Nema sumnje ako stranke i kandidati tako postupaju, treba očekivati i da će znatno veći broj građana posećivati njihove internetske stranice, jer konstatujmo još jedanput nedovoljna posećenost web stranicama posledica je načina na koji kandidati pristupaju internetu i načinu kako se odnose prema biračima.

\section{Zaključak}

Pitanje promene odnosa između građana i države usled primene novih IKT, odnosno da li internet menja tradicionalne oblike političkog delovanja bilo je u fokusu našeg istraživanja. U tom smislu, sagledavajući političku komunikaciju kroz kriterijume funkcionalnosti i efekata interneta možemo zaključiti da se njime mogu ostvariti bolji rezultati na izborima samo ako stranke i kandidati iskoriste njihov potencijal za dvosmernu komunikaciju. Naime, stranke će ostvariti bolju stranačku mobilizaciju a time i bolji rezultat ako koriste internet platformu za dijalog sa svojim članovima i simpatizerima. Uz, to, ako kandidati ostvare dijalog sa širim krugom građana, onda nema sumnje to može doprineti i većoj izbornoj participaciji i koristi celoj društvenoj zajednici. Međutim, činjenica je da u stvarnosti korišćenje interneta u poređenju sa drugim sredstvima nema najvažniju ulogu u informisanju birača o strankama i kandidatima.

$\mathrm{U}$ anketi koju smo sproveli u okviru istraživanja mogli smo utvrditi da ispitanici smatraju da je najvažnije sredstvo za donošenje odluke o davanju svog glasa razgovor sa porodicom i prijateljima, a zatim sledi uticaj interneta i televizije. Iz odgovora ispitanika u anketi mogli smo dalje zaključiti da se internet nalazi na drugom mestu što svakako ohrabruje kad se uporedi sa prethodnim kampanjama za predsedničke i parlamentarne izbore ali i ukazuje da kandidati nisu koristili internet još uvek na pravi način. Dakle, onako kako je većina kandidata koristila internet na izborima, internet nije mogao uticati na rezultate izbora, a nije koristio ni široj društvenoj zajednici. U izborima za gradonačelnika Niša 2016. godine a i u nizu dosadašnjih izbora, kod svih kandidata stvarne dvosmerne komunikacije nisu se koristile sa članovima svoje stranke, ni sa simpatizerima, a još manje sa širim krugom građana. U kontekstu našeg istraživanja bili smo u prilici da dođemo do saznanja i o rezultatima istraživanja u drugim zemljama koji govore da upotreba interneta u svrhu dijaloga stranka i kandidata sa biračima, koja ima za cilj povećanje uključenosti građana i širenje kruga politički aktivnih građana nije dovoljno razvijena.

Dakle, iz svih navedenih razloga internet platforma bi trebala da bude sredstvo za ostvarivanje dijaloga i mobilizacije pristalica, a ne sredstvo koje služi samo za promociju i 
oglašavanje. Istina je da se kroz medije poput televizije ili radija može oglašavati, ali treba imati na umu da se preko njih ne može ostvariti dvosmerna komunikacija. Upravo se putem interneta to može obezbediti i zato je internet mreža potrebna kako bi se zajedno sa građanima kreirala što realnija politika. Jer, ukoliko se zaista želi razvijati istinsko demokratsko društvo, onda je zato bitan preduslov postojanje demokratske rasprave u društvu u kojoj internet platforma može i mora imati krucijalnu ulogu.

\section{Literatura}

[1] Wilhem, A., G. (2004). Digital Nation-Toward an Inclusive Information Society, MIT Press, str. 103-104.

[2] URL: http:// www.srbija.sr.gov.yu/vesti/dokumenti_sekcija.php?id=45678)

[3] URL: Strategija razvoja informacionog društva do 2020, SI. glasnik RS br 51/2010.

[4] URL: www.slobodnaevropa.org

[5] Vojkan, Vasković \& Miroslav, Lutovac, (2009) Elektronsko poslovanje, Novi Pazar: DUNP, str. 33.

[6] URL: http:infokabinetbp.weebly.com/informaciono_druscarontovo.html

[7] Dušan Babić, (2010) Dometi i uticaj interneta u BiH u kontekstu širenja jezika mržnje i duha netolerancije. Monitoring/analiza portala. Radojko Udovičić (ur). Internet. Internet - sloboda bez granica? Analiza komentara na web portalima i preporuke za bolju komunikaciju. Sarajevo: Media plan institute, str. 67.

[8] Peter Dahlgren (1996) Media logic in Cyberspace: Repositioning Journalism and its Public, Jurnalism at the Crossroads, Vol 3, No3, p. 59-72.

[9] URL: https:// sr.wikipedia.org/wiki/hipertekst.

[10] Lejla Turčilo (2006) On-line komunikacija i off-line politika u BiH, Sarajevo: Internews BiH, str.26-29, 33.

[11] Christina Holtz-Bacha, (1998) Fragmentierung der Gesellschaft durch das Internet. In: Gellner, Winand/Korff,Firtz, von(Hrsg): Demokratie und Internet. Baden-Baden: Nomos, s 219-226.

[12] Vladimir Štambuk, Internet i politika, 1999, Beograd: Verzalpress, str. 7, 222.

[13] Sloboda izražavanja na internetu (ur). Jelena Surčulija, 2010. Beograd: Centar za razvoj interneta, str. 20.

[14] URL: www.cmv.org.rs/wp-content/uploads/dowuloads/2011/09/politička-komunikacija-nainternetu-fmal.pdf

[15] URL: www.mc.rs-novi-mediji-predizborna kampanja.1178.html

[16] Predrag Haramija, Politička komunikacija putem interneta - funkcionalna i moralna dimenzija, Obnov, život, 2014, 69, 4, str. 447-460

[17] Aaron Smit, Lee Rainie, The internet and the 2008 electrn, Pew Internet /American Life Project, june 15, 2008. Dostupno na:

www.pewinternet.org/:/media?Files?Reports/2008/PIP_2008_electron.pdf.

[18] URL: http:// manjgura.ha/blog/special-barack-obama-prvi-čovek-koji-je-iskoristio-punu-snaguinterneta-društvenih-mreža

[19] URL: http://politika.com/utjecaj-interneta-na-rezultate-izbora

[20] Carolin Wezel, Much Ado about nothing? The German Federal Elections 2002. on the web, Bertelsmann Foundation, 29.11.2002, dostupno na: http://www. artefaktum.hu/btk03osy/wezwl.htm 
[21] Oliver Falck, Robert Gold, Stephan Heblich, Voting Behavior and the internet, Forschungsinstitut zur Zukunft der Arbeit/Institute for the Study of labor, May 2012, dostupno na: http;// ftp.iza.org/dp6545.pdf

[22] URL: https:// wwwbi.irb.hr/563026

[23] Andrew Ksmarck, u: Jennifer Stromer-Gallez, On-line Interaction and Why Candidates Avoid It, Journal of Comunication, 2000, 50, str. 115

[24] URL: https://labs.rs/sr/onlajn-iyborna-kampanja-u-srbiji/

[25] Predrag Haramija, Internet i izbormna kampanja-svojstva izbora za gradonačelnika grada Zagreba, 2013, Nova prisutnost, 2014, 12,3, str. 345.

[26] URL: http:// ftp. iza.org/dp545.pdf

[27] Karina Pedersen, and J. Saglie, New Technology in Ageing Parties. Internet Use Danish and Norwegain Parties, Party Politica, 2005, 11, 3, 350-377.

[28] Steven Ward, Rachel Gibson, Wainer Luoil, Online participation and Mobilisation in Britain: Hype, and Reality, Hansard Society for Parliamentary Government 2003, Parliamentary Affairs, 2003., 56, 622-668.

[29] Andrew, Chadwick, Internet Politics-States, Citiezens and New Commmunication Tehnologies, Oxford University Press, 2006, str.134-143

[30] Andrew Chadwick, The Uinternet, Political Mobilization and Organizational Hzbridity: "Deanspace“, MoveOn.org and the 2004 US Presidental Campaign, Political Studies Association of the United Kingdom Annual Conference, University of Leeds, April 5th-7th, 2005., (dostupno na: http://

195.130.87.21:8080/dspace/bitstream/123456789/1027/1/The\%20internet,\%20political1\%20mobili zation\%20and\%20organizational\%20hybridity.pdf

[31] URL:http:// draganađermanovic.com/objavljeni-autorski-tekstovi-intervju/politika-internet-tanjug/

[32] URL: https:// www.academia.edu/16828354/članak_politička_komunikacija. 